Research Trainee

\title{
Indigenous Women's Stress and Postpartum Depression: Discussions from the Canadian Maternity Experiences Survey and Indigenous Maternity Narratives
}

\author{
Jennifer Leason
}

\section{A R T I C LE IN F O}

\section{Keywords:}

Indigenous women

Mothers

Pregnancy

Stress

Postpartum depression

Maternity experiences

Narratives

https://doi.org/10.32799/ijih.v16i2.33180

\begin{abstract}
A B S T R A C T
This doctoral research highlights Indigenous women's experiences of stress and postpartum depression (PPD) through secondary quantitative analysis of the Public Health Agency of Canada's Canadian Maternity Experiences Survey (2009) and qualitative Indigenous maternity narratives. Indigenous women's responses to the survey demonstrate that Indigenous women experience 1.9 times higher odds of PPD and are 1.5 times as likely to be diagnosed with depression prior to pregnancy, compared to Canadian women. Indigenous women are also 1.3 times as likely to experience higher levels of stress and 3.3 times as likely to experience three or more stressful life events. While the survey demonstrates higher rates of stress and PPD, it is not culturally or contextually relevant. Therefore, Indigenous maternity narratives from 10 Indigenous mothers in 2015 further contextualize experiences of stress and PPD to include narratives related to adverse social determinants of health and impacts of colonialism. The research includes a discussion on the limitations of previous maternity research and the limits of clinical-medical assessments and diagnosis of stress and PPD in Indigenous populations. The research concludes with recommendations for additional maternity experiences research and ways to support Indigenous women, infants and children, birth partners, families, and communities.
\end{abstract}

\section{A UTHOR INFO}

Jennifer Leason, PhD, Assistant Professor, Indigenous Peoples' Health, Department of Anthropology \& Archaeology, University of Calgary, Calgary, Alberta, Canada. Email: jennifer.leason@ucalgary.ca 


\section{Relationship \\ Boozhoo Aniin Keesis Sagay Egette Kwe nindiznikaz. Pine Creek nindinjoba. My} Anishinaabek name is First Shining Rays of Sunlight woman and I am a member of the Pine Creek Indian Band, Manitoba. As an Indigenous woman, mother, aunt, researcher, and intergenerational residential school survivor, I am passionate about alleviating maternal-child health disparities and inequities. This research is one of the key findings from my doctoral dissertation (Leason, 2017) that demonstrates Indigenous women's experiences and contexts of stress and postpartum depression. This research was funded by the Canadian Institutes of Health Research - Institute of Aboriginal Peoples' Health doctoral research award (Code: 201110DQU265973-215964).

\section{Introduction}

Conception, pregnancy, birth, and early months of parenthood are extraordinary moments. However, they can also result in stress, anxiety, and postpartum depression (PPD). Research demonstrates a direct and indirect association between chronic stress and adverse pregnancy and birth outcomes (Andersson et al., 2004; Gilbert et al., 1999), including low birth weight (Hobel et al., 2008; Lobel et al., 2008), preterm birth (Borders et al., 2007), and increased risk of PPD (Clout \& Brown, 2015). PPD is defined as a depressive episode that occurs after the birth of one's baby, and it can last several weeks or months (Wisner et al., 2010). It is estimated that approximately $10 \%$ to $12 \%$ of women experience PPD symptoms such as loss of pleasure, difficulty concentrating, change in appetite, difficulty with sleep, sadness, and disinterest in the baby, family, and friends (CAMH, n.d.). Although there is no single cause, increased risk is attributed to physical and emotional changes, personal or family history of depression, weak support systems, and socioeconomic stressors (Séjourné et al., 2011).

In Canada, Indigenous women are more likely to experience PPD, and rates are as high as $15 \%$ to $30 \%$ (Nelson et al., 2018). Chronic stress during pregnancy (Kingston et al., 2012) and PPD are important topics when addressing Indigenous perinatal health disparities (Chen et al., 2015; Gilbert et al., 2015; Smylie, 2012; Smylie et al., 2010). Adverse birth outcomes occur more frequently among First Nations, Inuit, and Métis women than among non-Indigenous women, including more preterm births for Inuit (11.4 per 100 births); higher large-forgestational-age First Nations births (20.9 per 100 births), double the rate of infant mortality, and 7 times the rate of sudden infant death syndrome among First Nations and Inuit (Sheppard et al., 2017). Indigenous health disparities are the result of adverse social determinants of health, including socioeconomic inequities, structural and systemic barriers, and immediate and ongoing impacts of colonialism (Greenwood et al., 2015; King et al., 2009; Leason, 2018; Reading \& Wien, 2013). Indigenous women face additional barriers related to racism, sexism, and colonialism (Bourassa et al., 2009) when accessing maternal-child health care (Downey \& Stout, 2011). Previous research demonstrates Indigenous women's invalidating encounters with health care (Narine, 2013; Varcoe et al., 2013), which negatively impact the utilization of health services (Tait Neufeld, 2014), such as late and/or inadequate use of prenatal and postpartum 
supports (Feijen-de Jong et al., 2012). However, it is equally important to celebrate the strength, resiliency, and persistence of Indigenous women and mothers who continue to resist oppressive models of motherhood, dominant culture, patriarchy, and colonialism (Anderson, 2011; LavellHarvard \& Corbiere Lavell, 2006). By understanding the current rate of PPD and the underlying causes related to emotional, relationship, financial, and traumatic stressors, we can then identify ways to address perinatal health disparities and support Indigenous women, children, families, and communities.

Population and public health survey research is based on biomedical and clinical reductionist and quantitative methods. By contrast, Indigenous research is based on cultural orientations, oral traditions, and narratives (Kovach, 2010). Indigenous research is interconnected and relational (Wilson, 2008), and as a result, it is often qualitative.

Like two sides of a coin, the research described in this paper integrates both quantitative and qualitative research. It includes a secondary data analysis (Phase I) of Indigenous women's responses to the Canadian Maternity Experiences Survey (MES; Public Health Agency of Canada [PHAC], 2009), followed by in-depth maternity narratives (Phase II) from 10 Indigenous mothers residing in the Okanagan region of the province of British Columbia (BC), Canada.

\section{Phase I: Canadian Maternity Experiences Survey (MES)}

\section{Methods for Phase I: MES}

The first and only MES administered in Canada in 2006 consists of 300+ questions on women's experiences before conception and during pregnancy, birth, and early months of parenthood (Chalmers et al., 2008; Dzakpasu et al., 2008). The research protocol was reviewed by Health Canada's Science Advisory Board and Research Ethics Board, and by the Federal Privacy Commissioner. Approval was received prior to implementation from Statistics Canada's Policy Committee (Chalmers et al., 2008, p. 2). The MES identified recent immigrant, young (age 15-18), and Indigenous women to be at higher risk of adverse pregnancy outcomes and that specific results would be produced through focused publications (PHAC, 2009, p. 11).

Subsequent focused publications were never produced. As a doctoral student, I accessed the data and disaggregated Indigenous women's responses. The research questions included:

1. What are Indigenous women's responses to the MES?

2. Do Indigenous women's responses to the MES differ from those of the general Canadian population?

A complete analysis of Indigenous women's responses is included in my dissertation (Leason, 2017).

\section{Sample}

Of the total 6,425 MES respondents (including Indigenous respondents), the sample included 410 self-identified Indigenous women representing 6\% of the total MES sample. Indigenous participants included 41.5\% First Nations women residing off reserve $(n=170)$; 
34.6\% Métis $(n=142)$, and 21.7\% Inuit $(n=89)$; another 2.2\% $(n=9)$ stated they were Indigenous but did not know if they were First Nations, Métis, or Inuit. Unfortunately, the MES excluded First Nations women residing on reserve, incarcerated women, and women whose children were not living with them at the time of the survey. Therefore, the sample does not include Indigenous women residing on reserve or subpopulations of incarcerated women or those whose children have been apprehended. While it was my intention to disaggregate all responses by First Nations, Métis, and Inuit responses, this was not always possible due to Statistics Canada disclosure control rules that suppress responses on cell sizes less than five. Therefore, some of the responses listed below are aggregated into a single Indigenous category and include all 410 Indigenous responses.

\section{Data Analysis}

The data were accessed through the Canadian Research Data Centre Network (https://crdcn.org). The analysis was conducted at the University of British Columbia from May to June 2014. Data analysis was done using SPSS Version 10.2 and included descriptive statistics of Indigenous women's responses to the MES questions (Leason, 2017). Following the descriptive analysis, a two-by-two frequency table was used to compare the relative odds of increased number, type, and frequency of stress and PPD (outcome of interest) between Indigenous and non-Indigenous participants (variable of interest). A 95\% confidence interval (CI) and odds ratio (OR) greater than 1 demonstrated higher odds compared to the reference group.

\section{Measures}

This paper includes Indigenous women's responses to the Pregnancy Risk Assessment Monitoring System (PRAMS; Gilbert et al., 1999) and the Edinburgh Postpartum Depression Scale (EPDS; Cox et al., 1987). The PRAMS variables include self-reported levels of stress, number of stressful life events, and experiences of emotional, relationship, financial, and traumatic stressors. The EPDS is a set of 10 screening questions that can indicate whether a parent has symptoms that are common in women with depression and anxiety during pregnancy and in the year following the birth of a child (Perinatal Services BC, n.d.). An Edinburg score of 10-12 indicates risk of PPD and a score of $13+$ indicates PPD.

\section{Results for Phase I: MES}

Stress

Responses to the PRAMS indicated that compared to non-Indigenous women, Indigenous women were at higher odds (OR 1.3, 95\% CI $[1.2,1.5])$ of describing their experience of the first few months of parenthood as "very stressful." Indigenous women were also at higher odds (OR 3.3, 95\% CI [3.0, 3.7]) of experiencing three or more stressful life events. The subjective experience of stress varied between Indigenous and non-Indigenous women and among First Nations, Métis, and Inuit women, thus illustrating the unique and diverse experiences. For First Nations mothers, $41.8 \%$ stated that the most common stressful life event included moving to a 
new address, followed by being kicked, hit, slapped or physically hurt by their partner (33.8\%), and someone close to them had a bad problem with drinking or drugs (31.5\%). For Métis mothers, the top three stressors included $43.5 \%$ who moved to a new address, followed by someone who was sick and had to go to the hospital (29.9\%), and someone close to them had a bad problem with drinking or drugs (29.3\%). The top three stressors for Inuit mothers included $45.1 \%$ who were kicked, hit slapped or physically hurt by their partner, moving to a new address $(25.2 \%)$ and someone close to them had a bad problem with drinking or drugs $(29.3 \%)$ (Table 1).

\section{Table 1}

Indigenous, First Nations, Métis, and Inuit Women's Stress Ratings, Number of Stressful Life Events, and Types of Stress Related to the Pregnancy Risk Assessment Monitoring System (PRAMS), Canadian Maternity Experiences Survey (MES), 2006-2007

\begin{tabular}{|c|c|c|c|c|}
\hline Stress-related variable & $\begin{array}{c}\text { Total MES } \\
(N=410) \\
\%\end{array}$ & $\begin{array}{c}\text { First Nations } \\
(n=170) \\
\%\end{array}$ & $\begin{array}{c}\text { Métis } \\
(n=142) \\
\%\end{array}$ & $\begin{array}{c}\text { Inuit } \\
\left(\begin{array}{c}n=89) \\
\%\end{array}\right.\end{array}$ \\
\hline \multicolumn{5}{|l|}{ Stress rating } \\
\hline Not stressful & 43 & 37.2 & 39.7 & 40.9 \\
\hline Somewhat stressful & 45 & 47.5 & 44.4 & 45.5 \\
\hline Very stressful & 12 & 15.3 & 16 & 13.6 \\
\hline \multicolumn{5}{|l|}{ Number of stressful life events } \\
\hline None & 39.1 & 17.9 & 24 & 14.5 \\
\hline 1 event & 27.8 & 18 & 23.6 & 22.4 \\
\hline 2 events & 16.0 & 23.2 & 12.5 & 18.3 \\
\hline 3 events (or more) & 17.1 & 40.8 & 39.9 & 44.8 \\
\hline \multicolumn{5}{|l|}{ Emotional stressors } \\
\hline $\begin{array}{l}\text { Someone close to you was sick and went to } \\
\text { hospital }\end{array}$ & 21.9 & - & 29.9 & - \\
\hline A close family member died & 15.6 & 29.0 & 22.1 & 35 \\
\hline $\begin{array}{l}\text { Someone close had a bad problem with } \\
\text { drinking or drugs }\end{array}$ & 9.0 & 31.5 & 29.3 & 24.8 \\
\hline \multicolumn{5}{|l|}{ Relationship stressors } \\
\hline $\begin{array}{l}\text { Got separated or divorced from your } \\
\text { husband or partner }\end{array}$ & 4.6 & 15.8 & 13.7 & 24.4 \\
\hline $\begin{array}{l}\text { You and your husband/partner argued more } \\
\text { than usual }\end{array}$ & 16.3 & 24.5 & - & 20.2 \\
\hline $\begin{array}{l}\text { Husband/partner said they did not want you } \\
\text { to be pregnant }\end{array}$ & 4 & - & - & - \\
\hline Involved in a physical fight & 1.6 & 10.1 & 4.4 & 10 \\
\hline $\begin{array}{l}\text { You or husband/partner went to jail or } \\
\text { detention centre }\end{array}$ & 1.1 & - & - & 13.5 \\
\hline
\end{tabular}




\section{Table 1 con't}

\begin{tabular}{|c|c|c|c|c|}
\hline Stress-related variable & $\begin{array}{c}\text { Total MES } \\
(N=410) \\
\%\end{array}$ & $\begin{array}{c}\text { First Nations } \\
(n=170) \\
\%\end{array}$ & $\begin{array}{c}\text { Métis } \\
(n=142) \\
\%\end{array}$ & $\begin{array}{c}\text { Inuit } \\
(n=89) \\
\%\end{array}$ \\
\hline \multicolumn{5}{|l|}{ Financial stressors } \\
\hline Moved to a new address & 28.3 & 41.8 & 43.5 & 25.2 \\
\hline Husband or partner lost job & 7.5 & 7.8 & 8.4 & - \\
\hline $\begin{array}{l}\text { Lost your job even though you wanted to go } \\
\text { on working }\end{array}$ & 5.7 & 7.4 & 8.9 & 4.3 \\
\hline Bills you couldn't pay & 11.4 & - & 19.3 & 25.4 \\
\hline \multicolumn{5}{|l|}{ Traumatic stressors } \\
\hline $\begin{array}{l}\text { You were kicked, hit, slapped, or physically } \\
\text { hurt by your partner }\end{array}$ & 10.9 & 33.8 & 25.2 & 45.1 \\
\hline Homeless & 1.0 & 3.9 & - & 1.7 \\
\hline
\end{tabular}

Note. Statistics based on cell sizes less than 5 (indicated with a dash) were suppressed per Statistics Canada disclosure control rules.

\section{Postpartum Depression}

Compared to the total MES participants, Indigenous women were at higher odds $(O R 1.5$, $95 \%$ CI $[1.3,1.7])$ of being prescribed antidepressants or being diagnosed with depression prior to their pregnancy. Compared to the total MES participants, Indigenous women were at higher odds of experiencing PPD (OR 1.9, 95\% CI [1.6, 1.9]), with younger Indigenous mothers aged 15 to 19 years of age being at the highest risk (Table 2).

\section{Table 2}

Proportion of Indigenous, First Nations, Métis, and Inuit Women Who Were Diagnosed With Depression, or Identified as At Risk for Postpartum Depression, per the Edinburgh Postpartum Depression Scale, Canadian Maternal Experiences Survey, 2006-2007

\begin{tabular}{|l|c|c|c|c|c|}
\hline \multicolumn{1}{|c|}{ PPD variable } & $\begin{array}{c}\text { Total MES } \\
(N=6,421) \\
\%\end{array}$ & $\begin{array}{c}\text { Indigenous } \\
(n=410) \\
\%\end{array}$ & $\begin{array}{c}\text { First } \\
\text { Nations } \\
(n=170) \\
\%\end{array}$ & $\begin{array}{c}\text { Métis } \\
(n=142) \\
\%\end{array}$ & $\begin{array}{c}\text { Inuit } \\
(n=89) \\
\%\end{array}$ \\
\hline $\begin{array}{l}\text { EPDS score } \\
\text { 13+ indicative of PPD } \\
10-12 \text { at risk for PPD }\end{array}$ & 7.5 & 14 & 13.6 & 9.3 & 19 \\
\hline $\begin{array}{l}\text { Prescribed antidepressants/ } \\
\text { diagnosed with depression } \\
\text { before pregnancy }\end{array}$ & 15.5 & 19.5 & 21.4 & 27.9 & 9.2 \\
\hline
\end{tabular}


Table 2 con't

\begin{tabular}{|l|c|c|c|c|c|}
\hline \multicolumn{1}{|c|}{ PPD variable } & $\begin{array}{c}\text { Total MES } \\
(N=6,421) \\
\%\end{array}$ & $\begin{array}{c}\text { Indigenous } \\
(n=410) \\
\%\end{array}$ & $\begin{array}{c}\text { First } \\
\text { Nations } \\
(n=170) \\
\%\end{array}$ & $\begin{array}{c}\text { Métis } \\
(n=142) \\
\%\end{array}$ & $\begin{array}{c}\text { Inuit } \\
(n=89) \\
\%\end{array}$ \\
\hline EPDS score by age & & & & & \\
15-19 years of age & 14 & 27.3 & & \\
13+ indicative of PPD & 10 & 15.4 & & \\
10-12 at risk for PPD & 9.3 & 16.9 & & \\
20-24 years of age & 9 & 7.3 & & \\
13+ indicative of PPD & 5.5 & 7.7 & & \\
10-12 at risk for PPD & 8.7 & 10.5 & & \\
25-29 years of age & 8.2 & 8.1 & & \\
13+ indicative of PPD & 8 & 9.9 & & \\
10-12 at risk for PPD & & & \\
30+ years of age & & & \\
13+ indicative of PPD & & & \\
$10-12$ at risk for PPD & & & & \\
\hline
\end{tabular}

Note . EPDS = Edinburgh Postpartum Depression Scale; MES = Maternal Experiences Survey; $\mathrm{PPD}=$ postpartum depression .

\section{Limitations for Phase I: MES}

Not only did the MES Indigenous sample exclude subpopulations, but under sampling also affected data quality and bivariate relationships did not adjust for confounding variables. In addition, the MES did not account for the complexities of social life, cultural diversity, or the socioeconomic context in which Indigenous women live. The questions were primarily biomedical and clinical, and did not include Indigenous women's perspectives on traditional wellness and impacts of racism or colonialism. Many of the public health questions were deficit based and did not consider the strengths and resiliency of Indigenous women, mothers, and communities.

\section{Phase II: Indigenous Maternity Narratives_Decolonized and Indigenous Methodology}

\section{Methods for Phase II: Maternity Narratives}

Using decolonized and Indigenous methodologies (Smith, 1999), I asked women to share their maternity narratives that included strengths, wholistic perinatal wellness, and epistemologies of mothering. Indigenous mothers' narratives provided a rich understanding of the diversity and complexity of Indigenous women's maternity experiences. A complete description of these Indigenous women's maternity narratives is included in my dissertation (Leason, 2017). For purposes of this paper, I will highlight Indigenous women's voices, experiences, and perceptions to better understand and contextualize the stress they experienced and narratives about stress and PPD. This research was granted ethics approval by the University of British Columbia Okanagan Behavioral Research Ethics Board on 19 November 2014 (Certificate number H14-02248). 


\section{Sample}

Ten semistructured, one-on-one interviews (kitchen table conversations) were conducted from 29 January to 8 April 2015. In addition to exploratory questions, specific questions covered sociodemographic information (Table 3); prenatal, labour, birth, and postpartum experiences; maternal stress; and PPD. All interviews were recorded and transcribed. An open call for participants included women who self-identified as First Nations, Métis, or Inuit and resided in the Okanagan region of BC; were 16 years of age or over; and gave birth between January 2012 and October 2014. The participants were different from the MES sample. The names used below are pseudonyms.

\section{Table 3}

Participant Demographic Information $(\mathrm{N}=10)$

\begin{tabular}{|l|c|}
\hline Demographic variable & $\begin{array}{c}\text { Number of } \\
\text { participants }\end{array}$ \\
\hline Self-identified as: & 5 \\
First Nations (Status Indian) & 2 \\
First Nations (Non-Status Indian) & 2 \\
Métis & 1 \\
Indigenous (stated but did not know which group) & \\
\hline Place of residence & 7 \\
Urban & 3 \\
On reserve & \\
\hline Living arrangements & 2 \\
Homeowner & 5 \\
Rental & 3 \\
Living with family members & 2 \\
\hline Age & 3 \\
16 to 19 years of age & 4 \\
20 to 24 years of age & 1 \\
25 to 29 years of age & \\
30+ years of age & 1 \\
\hline Highest level of education & 3 \\
Less than high school & 5 \\
High school graduate & 1 \\
Some postsecondary and/or college & \\
Bachelor's degree & 1 \\
\hline Total household income & 1 \\
0 to \$14,999 & 2 \\
\$15,000 to \$19,999 & 3 \\
\$20,000 to \$29,999 & 3 \\
\$30,000 to \$39,999 & \\
\hline Marital status & \\
Married or living with partner & \\
Divorced, widowed, or separated & \\
Single & \\
& \\
\hline
\end{tabular}


Table 3 con't

\begin{tabular}{|l|c|}
\hline Demographic variable & $\begin{array}{c}\text { Number of } \\
\text { participants }\end{array}$ \\
\hline Number of children & 3 \\
One child & 7 \\
More than one child & \\
\hline
\end{tabular}

\section{Thematic Content Analysis}

Transcripts of the conversations were entered and analyzed using MAXQDA Version XI. Thematic content analysis (Green \& Thorogood, 2004) was used to organize the narratives and identify themes. The recurrent or common themes serve as a means of evoking additional conversation about the underlying phenomena, relationships among the themes that emerge, and the context(s) in which they occur. The quotes presented below highlight the context of Indigenous maternity experiences related to stress(ors) and PPD.

\section{Results for Phase II: Maternity Narratives}

\section{Stress}

Participants described experiences of stress as feeling overwhelmed, alone, and isolated, with limited supports and access to services. All participants described various forms and impacts of stress in their life that spanned emotional, relationship, financial, and traumatic stressors. The findings below will build upon and contextualize the PRAMS stressors and present additional stressors identified by the participants.

\section{Emotional Stressors}

PRAMS (Gilbert et al., 1999) identifies three main emotional stressors: (a) someone close to you was sick and had to go to the hospital; (b) the death of a family member; and (c) someone close to you had a bad problem with drinking and drugs. As Susan described, the death of a family member coupled with financial stress can cause emotional stress and feelings of disconnection, isolation, and loneliness.

My aunt passed away last month and it was stressful being away from family. It's expensive to drive back. And it hurts not to see family. Family is everything for us. It hurts a lot not being able to see everyone and I worry about my mom. I worry about her a lot. (Susan, age 28, Status Indian, ${ }^{1}$ residing in urban area, intergenerational residential school survivor, raised in foster care)

Feelings of disconnection, isolation, and loneliness were expressed by other participants who lived in urban areas, away from their home communities and families. It is estimated that

\footnotetext{
1 "Status Indians," as defined by the Canadian government, are First Nations people who are entitled to have their names on the federal Indian Register. Only Status Indians are recognized as Indians under the Indian Act and are legally entitled to certain rights and benefits. Non-Status Indians are people who consider themselves Indian or members of a First Nation but who are not recognized as Indians by the Canadian government, either because they are unable to prove their status or because they have lost their status rights.
} 
over half $(51.8 \%)$ of the total Indigenous population live in metropolitan areas of at least 30,000 people (Statistics Canada, 2016). Indigenous urban migration and lack of access to community or social supports are also considerations for emotional stressors.

In addition to the three identified emotional stressors, participants also spoke about their family's or their partner's experiences of residential school and foster care. The emotional impacts of colonialism contributed to their emotional, relationship, and traumatic stress. Participants spoke about the direct and intergenerational impacts of colonialism and its contribution to death and addiction. Lisa shared how her mother and her grandparents attended residential school and how her experiences of foster care have shaped her maternity experience:

Our parents and their parents before us, they went through all the residential school stuff. My mom, she was abused. I think that's why she drank. She was trying to survive. She didn't raise us ... she didn't raise us, but she is my mom. By the time I was 12, I was in 14 different homes. Fourteen different foster homes! Wow, that's sad. That's not normal. But I forgive her, she tried. I think she did the best she could and I learned a lot from her. My mom and dad are my go-to people when I need something. They are the first two people I go to talk to, calm me down, and they just keep me level. I learned from experiences. I learned from the people that I looked up to. I learned from them. I learned forgiveness. Compassion. Our culture is huge ... and to do better for my kids. (Lisa, age 29 , Non-Status Indian, residing in urban area)

When relating her mother's experience of residential school Susan said that "we carry a lot from our past and I don't know how anybody can't."

My mom went to residential school and she had a nervous breakdown when we were young and she never got back from it. It was life-changing for her and I saw her go through those changes. I saw her live the good life, from that to depression. I remember her just sitting there at the kitchen table being a zombie. Not talking to anybody and not all there. And I didn't want that for myself. And seeing my mom go through that really gave me some perspective about why things are the way they are. I have my family that I worry about, and my mom's health. She's an alcoholic and I worry about her and her health and that's a lot of stress for me also. (Susan)

Patricia related her experiences growing up in foster care:

I don't know a whole lot about my family because I grew up in foster care. I was placed in foster care when I was four. My mom drank and I don't think my dad was around for much. All I can say is that I'm going to be a better mom than my mom ever was. (Patricia, age 22 , Indigenous, residing in urban area, raised in foster care)

In addition to women's own experiences of intergenerational residential school and foster care, Mary talked about her partner who also grew up in foster care and how his experiences affected her maternity experiences and contributed to emotional stress:

V OLUME 16 , IS S UE 2, $2021 \cdot 234$ 
It would be really interesting to know what it was like for him from his perspective and what it [pregnancy, birth, and parenting] was like for him. My parents are always really supportive of me but my partner grew up in foster care, so he's missing that unconditional love. He never really got that. He didn't have anybody to take care of him. There were periods he was out on the streets when he was a teenager. I think sometimes it's stressful because of his history and abuse that he's endured. I wish he would go to counselling to deal with some of the trauma he's endured. But, like I said, he's never had unconditional love, so trying to teach them what unconditional love is and what's normal or not normal and what is healthy or not. (Mary, age 27, Status Indian, residing on reserve)

In addition to impacts of colonialism, another emotional stressor for the participants was dealing with racism. Lisa recalled her experiences of racism:

I was in my doctor's office for a routine visit a month after my baby was born. The doctor is a recent immigrant physician. I asked her for a prescription for Tylenol, calcium, vitamin E, Polysporin, and Band-Aids, because it's covered under FNIB [FNIHB, First Nations Inuit Health Branch], but you need a prescription in order for it to be covered. She asked why and when I explained I was First Nations and that it was covered, she said, "I'm tired of you people abusing Tylenol, you ... Abinationals." When I corrected her and said we were Aboriginal, she said, "I'm tired of you people abusing medicare, you're a drain on Canada's medical care." I was so humiliated and embarrassed that I'll probably never go back again. (Lisa)

In addition to racism, participants expressed feelings of judgment when accessing mainstream health services, and some said they avoided support services for fear of child apprehension. Four of the 10 participants described "being watched" and the emotional stress from their experiences led to a delay in or lack of accessing mainstream health care.

I think there's a fear admitting that we can't do it or admitting that we're struggling-it's seen as a weakness-or because we are scared that the kids will be taken away. They're afraid of being labelled an unfit parent. That's a huge fear for me! When I think about it now, it still scares me inside, because it happens all the time. It happens all the time still ... kids are taken away. I guess it [dealing with things on her own] is just easier that way. I do feel so alone sometimes. (Lisa)

I didn't know where to go [for help while struggling]. I think it's that, I didn't know where to go and maybe I'm scared to go, so I just dealt with it on my own. [Interviewer: Why don't you reach out for help?] I guess because I was scared that they'd see me as a bad mom or that I was too messed up to take care of my baby. (Donna, age 17, NonStatus Indian, residing in urban area) 
The fear of accessing health care or reaching out for help is particularly concerning for Indigenous women who may be struggling with stressors, PPD, and thoughts of suicide.

I've struggled with suicide. I've struggled a lot. [Interviewer: Have you ever reached out for help?] Yeah, when I've needed it. My family has helped me. [Interviewer: What about health care providers or mental health professionals?] No, I'd rather not. I either choose to deal with it on my own or with family or friends. Less judgment. (Lisa)

\section{Relationship Stressors}

PRAMS (Gilbert et al., 1999) identifies five relationship stressors: (a) got separated or divorced from your husband or partner; (b) you and your husband or partner argued more than usual; (c) Husband or partner said they didn't want you to be pregnant; (d) involved in a physical fight; and (e) you or your partner went to jail or a detention centre. In addition to the identified stressors, participants also identified relationships with family, relationships with their children, and parenting or single parenting as relationship stress.

My kids stress me out. Parenting is difficult! Not to mention step-parenting. There's no manual. (Susan)

He [son, age 16] was getting into more trouble at school and was coming home and causing trouble. The whole house was in disarray. He's in Ontario right now. He had to go to Ontario because he was getting involved with other kids in the neighbourhood. (Lisa)

Mary also explained how family contributes to relationship stress.

My partner's brother is struggling with addictions right now and he's 22 years old. He drinks every day and he has mental health issues. He's on antidepressants. He has social anxiety. We went over there and he was drinking. I was talking to him and I said, "You've been struggling with this," and I asked, "When are you going to draw the line?" No one wants the same thing. No one wants to be an alcoholic. Is he going to have to end up in the hospital or die for him to realize it? Because even his mom was through this depression and she gets suicidal and ends up in the hospital once every 3 months and now she's in a low point. (Mary)

\section{Financial Stressors}

PRAMS (Gilbert et al., 1999) identifies four financial stressors: (a) move to a new address; (b) husband or partner lost their job; (c) you lost your job; and (d) bills you couldn't pay. Stress related to adverse conditions plays an integral part in the onset and expression of PPD. These stressors primarily focus on employment. However, Indigenous women's experiences as expressed by these participants included stress associated with obtaining an education, such as completing their high school diploma, attending college, or furthering their skills and training. Women identified stress associated with a lack of daycare and safe, affordable 
childcare; transportation limitations (no vehicle and lack of public transit); decreased Indian band funding and support for tuition and living costs; and stress associated with balancing work, school, and parenting (or lone parenting without support).

Financial stress included having enough money for tuition, training costs, and living expenses (rent, groceries, utilities, and increasing cell, telephone, and internet fees).

I worry about money all the time. I worry about how I'm going to pay the bills and if I have enough for rent. It's the third time I've been late with rent and I'm scared they'll ask me to leave. (Donna)

Women also identified food security as a stressor:

I'm stressed because some months I barely have enough to pay for rent and bills or food. Not to mention the cost of formula. I'm so grateful for the Friendship Centre and Good Food Box. (Donna)

Moving to a new address; access to safe, affordable, and reliable housing; and urban migration due to enhanced opportunities or escaping a violent relationship were identified as financial and traumatic stressors.

We're constantly moving. I swear to god we've moved like three times last year.

[Interviewer: Why did you keep moving?] Well, first we moved off the rez [reserve] and came here. I lived out on the reserve and I felt like I had to get out of there. It [the violence] just got to be too much. I left. I was scared, pregnant, and had nowhere to go. So I went into a women's shelter in the city and I thought I needed a new start from there. (Susan)

\section{Traumatic Stressors}

PRAMS (Gilbert et al., 1999) identifies two traumatic stressors: (a) you were kicked, hit, slapped, or physically hurt by your partner; and (b) homelessness. As discussed above, the immediate and intergenerational impacts of colonialism, as well as racism and sexism, represent additional traumatic stressors faced by Indigenous women.

\section{PPD}

Three of the 10 participants shared that they had suffered from PPD. However, there is a lack of understanding about the symptoms of PPD and resources for Indigenous women. This demonstrates the need to increase awareness and understanding, as well as resources and supports.

I don't think I really know [if I had PPD] because I just dealt with it on my own and never really reached out to anyone to talk about it. Who knows ... maybe I was? (Mary) 
Participants identified the need for social supports and talking to someone to ensure women are not isolated and suffering in silence. There is a need to explore models of quality care, including access to culturally relevant PPD programming and supports.

If you have a bad day, talk to somebody. Let it out, don't hold it in. Don't suffer in silence. I suffered in silence because I thought I had to be this strong woman and I didn't want people to see me fall. And so, I suffered in silence. (Lisa)

There has to be more programs in this area. In prenatal help there isn't enough and there's a lot of moms. I think that there needs to be more culturally safe programs, such as healthy eating programs and postpartum help. Learning about birth and birth plans, as well as access to doulas and midwives. (Mary)

Another recommendation is to support women through outreach programs and in-home visits, such as an "aunties" program.

I would like to see, like, an aunties program for someone to come drop in and see how I'm doing. A lot of our services we have to go there and it's difficult. We need more outreach. (Lisa)

Existing programs are often scheduled according to the needs of the organization, rather than the needs of Indigenous women.

Our emotions aren't on a schedule. For health care providers and program people to be present is important too. Just being there, listening, having tea, and just talking is good. Sometimes you just need to feel like you're not alone in this world. I think families need to be educated too [on PPD and how to support mothers] so they can help. I think there needs to be programs for families, not just women. (Donna)

\section{Strength-Based Narratives}

There is a need to focus on strength-based narratives of resilience and persistence as a way of looking "at birth instead of death, wellness instead of illness, positive behaviours instead of guilt" (Stout et al., 2001, p. 25). The women's narratives of intergenerational strength, resiliency, matriarchy, and ending negative cycles for themselves and their children highlight their resilience, persistence, strength, and superpowers as Indigenous warrior women.

I come from a long line of strong women. And it's that warrior woman in all of us that we pass down. It's that strong blood and we can't give up because of our babies. We were taught not to give up on our babies and to take responsibility.

You're not alone in your experience. Women are strong. A lot of people think they're not. They just need to realize they are [strong] and it takes time for that to happen. You need someone to say that. Yes, you're pregnant and you may be alone. You're strong, you're making a human being! I make humans, what's your superpower? (Susan)

V OLUME 16 , IS S UE 2, $2021 \bullet 238$ 


\section{Limitations for Phase II: Maternity Narratives}

The narrative research limitations include interpretation, scope, and generalizability. The 10 participants from the Okanagan are a small, nonrepresentative sample that is neither numerically nor qualitatively representative of the diversity of First Nations, Métis, and Inuit maternity experiences. However, the narratives provide an opportunity to engage in further narrative research to inform maternity experiences research discussed below.

\section{Discussion}

Findings from the PRAMS (Gilbert et al., 1999) assessment within the MES (PHAC, 2009) demonstrate that Indigenous mothers reported higher rates of emotional, relationship, financial, and traumatic stressors. However, the categories in the PRAMS assessment fail to capture the diversity, complexity, and context of Indigenous maternity experiences. The maternity narratives presented in this study include experiences of colonialism (e.g., residential schools and foster care), racism, as well as economic and social barriers to accessing perinatal and PPD supports and services. Additional research is needed to advance the validity of medical assessment tools such as PRAMS and ensure future research and assessment are culturally and contextually relevant. By engaging Indigenous women, families, and communities in maternity experiences narratives, we can then understand the diversity, complexity, and cultural contexts. This research can then inform community-based initiatives, programs, services, supports, and policies.

This paper demonstrates that Indigenous women have 1.9 times the risk of PPD compared to Canadian women generally, and that Indigenous women are 1.5 times as likely to be prescribed antidepressants and be diagnosed with depression prior to pregnancy. This finding raises questions about availability and accuracy of PPD rates in Indigenous communities, and about whether or how data are collected on the incidence and prevalence of PPD in First Nations, Métis, and Inuit communities and contexts. Additional research is needed to understand PPD rates, cultural definitions of PPD, and the delivery of psychosocial assessment in Indigenous communities. Key recommendations include addressing experiences of racism and systemic barriers, as well the need for culturally relevant and safe PPD supports and services specifically for Indigenous women and families. Inclusive research and wholistic models of perinatal health and wellness are needed to support women throughout their pregnancy journeys.

The exclusion of subpopulations demonstrates the need to expand maternity research to include the diverse and complex experiences of First Nations, Métis, and Inuit women residing on or off reserve, in urban, rural, or remote communities, and who may or may not be living with their infants and children. Not only did the MES exclude subpopulations of Indigenous women, but the questions posed were not culturally or contextually relevant. This is highlighted by Indigenous maternity narratives that expanded the categories of stress and experiences of PPD to include experiences of colonialism, violence, and racism. PRAMS did not include Indigenous experiences related to colonialism, racism, sexism, and structural barriers and inequities. Nor did it include experiences of stress related to education, childcare, food security, urban migration, 
and access to safe and affordable housing - factors that are often important to Indigenous women's experiences. Decolonized and Indigenous methodologies are also needed to inform future maternity experiences research that captures the diversity and complexity of Indigenous maternity experiences.

In addition, the questions posed by the MES were primarily biomedical, clinical, and deficit based. Throughout the maternity narratives, women highlighted their intergenerational resiliency, strength, and persistence. Further research that focuses on strengths and realities is needed to complement existing public health research. Additional research is also needed to include the experiences and perspectives of Indigenous men and birth partners, Elders, families, and communities.

\section{Conclusion}

Given the higher rates of PPD and stress experienced by Indigenous women compared to the general population of Canadian women, there is a need to better support Indigenous women, infants and children, birth partners, families, and communities. Further research is needed to inform more accurate assessment of rates of PPD within Indigenous communities, as well as to address the underlying causes related to adverse social determinants of health and emotional, relationship, financial, and traumatic stressors. By understanding maternal and child health from Indigenous perspectives, research can help understand health needs, gaps, barriers, and strengths as a way of improving Indigenous maternal-child health policies, programs, and practices.

\section{References}

Anderson, K. (2011). Life stages and Native women: Memory, teachings, and story medicine. University of Manitoba Press.

Andersson, L., Sundström-Poromaa, I., Wulff, M., Åström, M., \& Bixo, M. (2004). Neonatal outcome following maternal antenatal depression and anxiety: A population-based study. American Journal of Epidemiology, 159(9), 872-881. https://doi.org/10.1093/aje/kwh122

Borders, A. E. B., Grobman, W. A., Amsden, L. B., \& Holl, J. L. (2007). Chronic stress and low birth weight neonates in low-income population of women. Obstetrics \& Gynecology, 109(2), 331-338. https://doi.org/10.1097/01.aog.0000250535.97920.b5

Bourassa, C., McKay-McNabb, K., \& Hampton, M. (2009). Racism, sexism and colonialism: The impact on the health of Aboriginal women in Canada. In P. A. Monture \& P. D. McGuire (Eds.), First voices: An Aboriginal women's reader (pp. 293-304). Inanna Publications.

CAMH (Centre for Addiction and Mental Health). (n.d.). Postpartum depression. https://www.camh.ca/en/health-info/mental-illness-and-addiction-index/postpartumdepression

Chalmers, B., Dzakpasu, S., Heaman, M., \& Kaczorowski, J. (2008). The Canadian Maternity Experiences Survey: An overview of findings. Journal of Obstetrics and Gynaecology Canada, 30(3), 217-218. https://doi.org/10.1016/S1701-2163(16)32758-X 
Chen, L., Xiao, L., Auger, N., Torrie, J., Gros-Louis McHugh, N., Zoungrana, H., \& Luo, Z.-C. (2015). Disparities and trends in birth outcomes, perinatal and infant mortality in Aboriginal vs. non-Aboriginal populations: A population-based study in Quebec, Canada 1996-2010. PLoS ONE, 10(9), Article e0138562.

https://doi.org/10.1371/journal.pone.0138562

Clout, D., \& Brown, R. (2015). Sociodemographic, pregnancy, obstetric, and postpartum predictors of postpartum stress, anxiety and depression in new mothers. Journal of Affective Disorders, 188, 60-67. https://doi.org/10.1016/j.jad.2015.08.054

Cox, J. L., Holden, J. M., \& Sagovsky, R. (1987). Detection of postpartum depression: Development of the 10-item Edinburgh Postpartum Depression Scale. British Journal of Psychiatry, 150(6), 782-786. https://doi.org/10.1192/bjp.150.6.782

Downey, B., \& Stout, R. (2011). Young and Aboriginal: Labour and birth experiences of teen mothers in Winnipeg. Prairie Women's Health Centre of Excellence. http://www.pwhce.ca/pdf/youngAboriginal_Full.pdf

Dzakpasu, S., Kaczorowski, J., Chalmers, B., Heaman, M., Duggan, J., \& Neusy, E. (2008). The Canadian Maternity Experiences Survey: Design and methods. Journal of Obstetrics and Gynaecology Canada, 30(3), 207-216. https://doi.org/10.1016/S1701-2163(16)32757-8

Feijen-de Jong, E. I., Jansen, D. E. M. C., Baarveld, F., van der Schans, C. P., Schellevis, F. G., $\&$ Reijneveld, S. A. (2012). Determinants of late and/or inadequate prenatal healthcare in high-income countries: A systematic review. European Journal of Public Health, 22(6), 904-913. https://doi.org/10.1093/eurpub/ckr164

Gilbert, B. C., Shulman, H. B., Fischer, L. A., \& Rogers, M. M. (1999). The Pregnancy Risk Assessment Monitoring System (PRAMS): Methods and 1996 response rates from 11 states. Maternal and Child Health Journal, 3(4), 199-209. https://doi.org/10.1023/a:1022325421844

Gilbert, N. L., Auger, N., \& Tjepkema, M. (2015). Stillbirth and infant mortality in Aboriginal communities in Quebec. Statistics Canada, Catalogue No. 82-003-X. http://www.statcan.gc.ca/pub/82-003-x/2015002/article/14139-eng.pdf

Green, J., \& Thorogood, N. (2004). Qualitative methods for health research. SAGE Publications.

Greenwood, M., de Leeuw, S., Lindsay, N. M., \& Reading, C. (Eds.). (2015). Determinants of Indigenous Peoples' health in Canada: Beyond the social. Canadian Scholars' Press.

Hobel, C. J., Goldstein, A., \& Barrett, E. S. (2008). Psychosocial stress and pregnancy outcome. Clinical Obstetrics and Gynecology, 51(2), 333-348. https://doi.org/10.1097/GRF.0b013e31816f2709

King, M., Smith, A., Gracey, M. (2009). Indigenous health part 2: the underlying causes of the health gap. Lancet, Jul 4; 374(9683):76-85.

Kingston, D., Heaman, M., Fell, D., Dzakpasu, S., \& Chalmers, B. (2012). Factors associated with perceived stress and stressful life events in pregnant women: Findings from the Canadian Maternity Experiences Survey. Maternal and Child Health Journal, 16(1), 158-168. https://doi.org/10.1007/s10995-010-0732-2 
Kovach, M. (2010). Conversation method in Indigenous research. First Peoples Child \& Family Review, 5(1), 40-48. https://doi.org/10.7202/1069060ar

Lavell-Harvard, D. M., \& Corbiere Lavell, J. (Eds.). (2006). "Until our hearts are on the ground": Aboriginal mothering, oppression, resistance and rebirth. Demeter Press.

Leason, J. (2017). Exploring the complex context of Indigenous women's maternity experiences in the Okanagan Valley, British Columbia by expanding on Aboriginal women's responses to the Canadian Maternity Experiences Survey [Doctoral dissertation, University of British Columbia]. UBC Theses and Dissertations. https://open.library.ubc.ca/cIRcle/collections/ubctheses/24/items/1.0342345

Leason, J. (2018). Exploring the complex context of Canadian Indigenous maternity child-health through maternity experiences: The role of social determinants of health. Social Determinants of Health, 4(2), 54-97. https://doi.org/10.22037/sdh.v4i2.19504

Lobel, M., Hamilton, J. G., \& Canelle, D. T. (2008). Psychosocial perspectives on pregnancy: Prenatal maternal stress and coping. Social and Personality Psychology Compass, 2(4), 1600-1623. https://doi.org/10.1111/j.1751-9004.2008.00119.x

Narine, S. (2013). Racism, mistrust keep Aboriginal people from health care. Windspeaker, $30(11), 18$.

Nelson, C., Lawford, K., Otterman, V., Darling, E. (2018). Original quantitative researchMental health indicators among pregnant Aboriginal Women in Canada: results from the Maternity Experiences Survey. Health Promotion and Chronic Disease Prevention in Canada, 38(7/8), 269-276. https://doi.org/10.24095/hpcdp.38.7/8.01

Perinatal Services BC. (n.d.). Edinburgh Postpartum Depression Scale (EPDS). http://www.perinatalservicesbc.ca/health-professionals/professional-resources/healthpromo/edinburgh-postpartum-depression-scale-(epds)

Public Health Agency of Canada. (2009). What mothers say: The Canadian Maternity Experiences Survey. http://www.phac-aspc.gc.ca/rhs-ssg/pdf/survey-eng.pdf

Reading, C. L., \& Wien, F. (2013). Health inequalities and social determinants of Aboriginal Peoples' health. National Collaborating Centre for Indigenous Health. https://www.nccih.ca/docs/determinants/RPT-HealthInequalities-Reading-Wien-EN.pdf

Séjourné, N., Alba, J., Onorrus, M., Goutaudier, N., \& Chabrol, H. (2011). Intergenerational transmission of postpartum depression. Journal of Reproductive and Infant Psychology, 29(2), 115-124. https://doi.org/10.1080/02646838.2010.551656

Sheppard, A. J., Shapiro, G. D., Bushnik, T., Wilkins, R., Perry, S., Kaufman, J. S., Kramer, M. S., \& Yang, S. (2017). Birth outcomes among First Nations, Inuit and Métis populations. Health Reports, 28(11), 11-16. https://www150.statcan.gc.ca/n1/en/pub/82003-x/2017011/article/54886-eng.pdf?st=t6mAGlj7

Smith, L. T. (1999). Decolonizing methodologies: Research and Indigenous Peoples. Zed Books.

Smylie, J. (2012). Aboriginal infant mortality rate in Canada [Correspondence]. The Lancet, 380(9851), 1384. https://doi.org/10.1016/S0140-6736(12)61797-8

Smylie, J., Crengle, S., Freemantle, J., \& Taualii, M. (2010). Indigenous birth outcomes in 
Australia, Canada, New Zealand and the United States-An overview. The Open Women's Health Journal, 2010(4), 7-17. https://doi.org/10.2174/1874291201004010007

Statistics Canada. (2016).Stout, M. D., Kipling, G. D., \& Stout, R. (2001). Aboriginal Women's Health Research Synthesis Project final report. Retrieved from Centre of Excellence for Women's Health website: http://bccewh.bc.ca/wpcontent/uploads/2012/05/2001_Aboriginal-Health-Research-Synthesis-Project-FinalReport.pdf

Tait Neufeld, H. (2014). Patient and caregiver perspectives of health provision practices for First Nations and Métis women with gestational diabetes mellitus accessing care in Winnipeg, Manitoba. BMC Health Services Research, 14(1), Article 440. https://doi.org/10.1186/1472-6963-14-440

Varcoe, C., Brown, H., Calam, B., Harvey, T., \& Tallio, M. (2013). Help bring back the celebration of life: A community-based participatory study of rural Aboriginal women's maternity experiences and outcomes. BMC Pregnancy and Childbirth, 13, Article 26. https://doi.org/10.1186/1471-2393-13-26

Wilson, S. (2008). Research is ceremony: Indigenous research methods. Fernwood Publishing.

Wisner, K. L., Moses-Kolko, E. L., \& Sit, D. K. Y. (2010). Postpartum depression: A disorder in search of a definition. Archives of Women's Mental Health, 13, 37-40. https://doi.org/10.1007/s00737-009-0119-9 